\title{
CARACTERIZAÇÃO BIOFACIOLÓGICA DOS SEDIMENTOS DA BAÍA DE TODOS OS SANTOS, BRASIL
}

\author{
BIOFACIOLOGICAL CHARACTERIZATION OF THE SEDIMENTS OF THE TODOS OS \\ SANTOS BAY, BRAZIL
}

\section{Carolina de Almeida POGGIO ${ }^{1}$, José Maria Landim DOMINGUEZ ${ }^{1}$, Paulo de Oliveira MAFALDA JUNIOR ${ }^{2}$, Orane Falcão de Souza ALVES ${ }^{2}$ \\ ${ }^{1}$ Universidade Federal da Bahia, Instituto de Geociências. Rua Barão de Jeremoabo, s/n. Campus de Ondina. Salvador - BA. Email: cpoggio77@gmail.com; landim.jmd@me.com \\ ${ }^{2}$ Universidade Federal da Bahia, Instituto de Biologia. Rua Barão de Jeremoabo, s/n. Campus de Ondina. Salvador -BA. Emails: paulomafaldajr@ufba.br; orane@ufba.br}

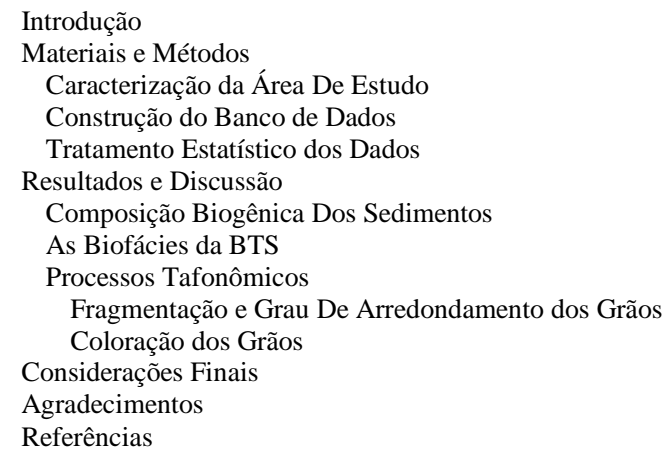

RESUMO - O estudo das partículas biogênicas dos sedimentos de fundo da Baía de Todos os Santos (BTS) foi realizado com o objetivo de investigar as biofácies como um instrumento de caracterização do ambiente sedimentar da baía. Através da análise de agrupamento foi possível estabelecer quatro biofácies bem definidas. Estas biofácies permitiram verificar uma transição da composição biogênica do interior da BTS onde, na maioria das vezes, os moluscos predominaram nos sedimentos, em relação à plataforma continental adjacente, onde as algas calcárias passaram a ser o componente principal. Com base nas características composicionais foi possível classificar a maior parte das assembleias biogênicas como parautóctones, ou seja, aquelas que não são transportadas para longe de seu hábitat original. Foi possível constatar que os processos tafonômicos registrados são o reflexo das condições ambientais da baía, um ambiente semi-fechado, apresentando geralmente energia baixa a moderada e uma grande diversidade de tipos de fundo.

Palavras-chave: bioclástos, tafonomia, Baía de Todos os Santos.

\begin{abstract}
The study of biogenic particles in the bottom sediments of the Todos os Santos Bay (TSB) was conducted in order to investigate the biofacies and active taphonomic processes as a characterization of the sedimentary environment. Through cluster analysis was possible to establish four distinct biofacies. These biofacies revealed that the transition from biogenic composition of the interior of the BTS where, most often, molluscs predominated in sediments in relation to the continental shelf, where the calcareous algae became the main component. Based on the compositional features and taphonomic was possible to classify most of the biogenic assemblage as parautóctones, those that are not transported far from their original habitat. It was possible to verify that the recorded taphonomic processes are the reflection of the environmental conditions of the bay, a semi-closed environment, generally having low to moderate energy and a great diversity of types of bottom.
\end{abstract}

Keywords: bioclasts, taphonomy, Todos os Santos Bay.

\section{INTRODUÇÃO}

As biofácies são formadas por associações de partículas sedimentares de origem biológica, produzidas por diversos tipos de organismos (Halfar et al., 2000).

Essas partículas, também chamadas de biogênicas, são originadas de estruturas biomineralizadas, tais como conchas, esqueletos, carapaças e tecas. Elas são produzidas principalmente por moluscos, briozoários, equinodermos, corais, algas calcárias, crustáceos e foraminíferos (Illing, 1954; Halfar et al., 2000). Atualmente, tem-se discutido muito a respeito das condições ambientais que podem influenciar na formação dessas associações.

Uma vez que são constituídas por esqueletos e tecidos endurecidos de organismos vivos, é esperado que fatores tais como temperatura, salinidade, profundidade, disponibilidade de nutrientes, turbidez da água e tipo de substrato 
tenham participação na sua formação, seja em pequena ou em grande escala (Less \& Buller, 1972; Wright \& Burges, 2005). Em se tratando de sedimentos atuais, até mesmo atividades antropogênicas, que causem alterações persistentes no ambiente, podem ser refletidas na sua composição (Bonetti et al., 2001) e, consequentemente, nas associações que serão formadas.

O estado de preservação das partículas biogênicas é uma questão que vem sendo bastante abordada em pesquisas recentes e está relacionada aos chamados processos tafonômicos. Estes atuam logo após a morte do organismo, quando sua estrutura biomineralizada irá compor o sedimento e passará a se comportar como uma partícula sedimentar. São processos físicos, químicos e biológicos, responsáveis pela alteração do tamanho, da cor e da forma dos grãos, que começam a atuar logo após a morte do organismo (Brett \& Baird, 1986; Callender et al., 1992).

Nessa condição, a partícula, que geralmente tem constituição carbonática, passará a sofrer desgastes durante sua permanência na interface água-sedimento, que determinarão seu estado de preservação (Behrensmeyer \& Kidwell, 1985). Em sedimentos recentes é possível encontrar uma fonte rica de variados dados tafonômicos, que podem ajudar a compreender melhor tanto os processos de fossilização, como a natureza da informação biológica preservada nos sedimentos (Behrensmeyer et al., 2000).

De forma semelhante à composição dos sedimentos, os processos tafonômicos são o reflexo das condições existentes no ambiente e sua análise é uma forma útil para caracterizar o ambiente deposicional (Kidwell et al., 1986; Brett \& Baird, 1986; Callender et al., 1992). Baseado nestes pressupostos, o presente trabalho teve como objetivo principal investigar as biofácies e os processos tafonômicos, fragmentação, grau de arredondamento e coloração, atuantes nos sedimentos da Baía de Todos os Santos como um instrumento de caracterização do ambiente sedimentar da referida baía.

\section{MATERIAIS E MÉTODOS}

\section{Caracterização da Área de Estudo}

A Baía de Todos os Santos (BTS) está localizada na região nordeste do Brasil (Figura 1). É considerada a segunda maior baía brasileira (Lessa et al., 2000) e apresenta um histórico considerável de atividades humanas em seu entorno. Observa-se em seu interior um conjunto de estuários e baías secundárias, como as de Iguape, de Aratu e da Ribeira, e 54 ilhas, das quais as maiores são Itaparica, Frade, Maré e Madre de Deus.

A maior parte da baía apresenta baixa profundidade, que geralmente não ultrapassa $10 \mathrm{~m}$. Pontualmente é possível verificar profundidades além dos 20m, como ocorre entre as Ilhas do Frade e Madre de Deus, na foz do rio Paraguaçu e no Canal de Salvador, podendo este último exceder localmente 50m (Bittencourt et al., 1976).

A BTS representa uma feição costeira com morfologia fortemente controlada por falhas, associadas à Bacia Sedimentar do Recôncavo, delimitada a oeste pela falha de Maragogipe e a leste pela falha de Salvador (Dominguez \& Bittencourt, 2009). Do ponto de vista oceanográfico, a referida baía possui características marinhas ao longo de todo o ano
(Lessa et al., 2001).

Os estudos dos sedimentos superficiais do fundo da BTS iniciaram-se há mais de 30 anos e sempre destacaram suas características texturais. Recentemente, Dominguez \& Bittencourt (2009) caracterizaram quatro fácies sedimentares principais nesta baía da seguinte forma: (i) fáceis de areia quartzosa, composta principalmente por grãos de quartzo e alguns biodetritos; (ii) fácies lama, constituída por argila, silte e pouca areia, alguns componentes biogênicos, fragmentos de vegetais e pelotas fecais; (iii) fácies areia e cascalho biodetríticos, composta por mais de $50 \%$ de componentes biogênicos, alguns grãos de quartzo e pouca argila; e (iv) fácies mista, constituída por uma mistura, em diversas proporções, de areia quartzosa, lama e biodetritos.

Além da heterogeneidade das condições do fundo, a BTS apresenta uma considerável variedade de ambientes, dentre eles: praias arenosas, rochosas, lodosas, extensos manguezais, além dos recifes coralíneos. Estes últimos bordejam, quase continuamente, a parte leste e sudeste da Ilha de Itaparica, estão presentes ao redor da Ilha de Madre de Deus e no litoral de Salvador, bem como formam bancos entre as Ilhas 
de Maré e dos Frades (Dutra et al., 2006). Tal diversidade ambiental favorece a biodiversidade associada ao fundo desta baía e deverá estar registrada também nos sedimentos biogênicos produzidos por elas.

\section{Construção do Banco de Dados}

Os sedimentos foram amostrados em 32 estações (Figura 1), utilizando-se um busca-fundo do tipo van Veen e os dados de profundidade foram obtidos por meio de ecossonda. Em laboratório, todas as amostras foram submetidas aos procedimentos de peneiramento (frações > 0,062), em intervalos de um phi, e de pipetagem (frações < 0,062) (Suguio, 1973), para a obtenção dos dados granulométricos. O teor de carbonato das amostras foi estimado por meio de digestão em ácido clorídrico e o conteúdo orgânico utilizando-se água oxigenada (Gross, 1971).

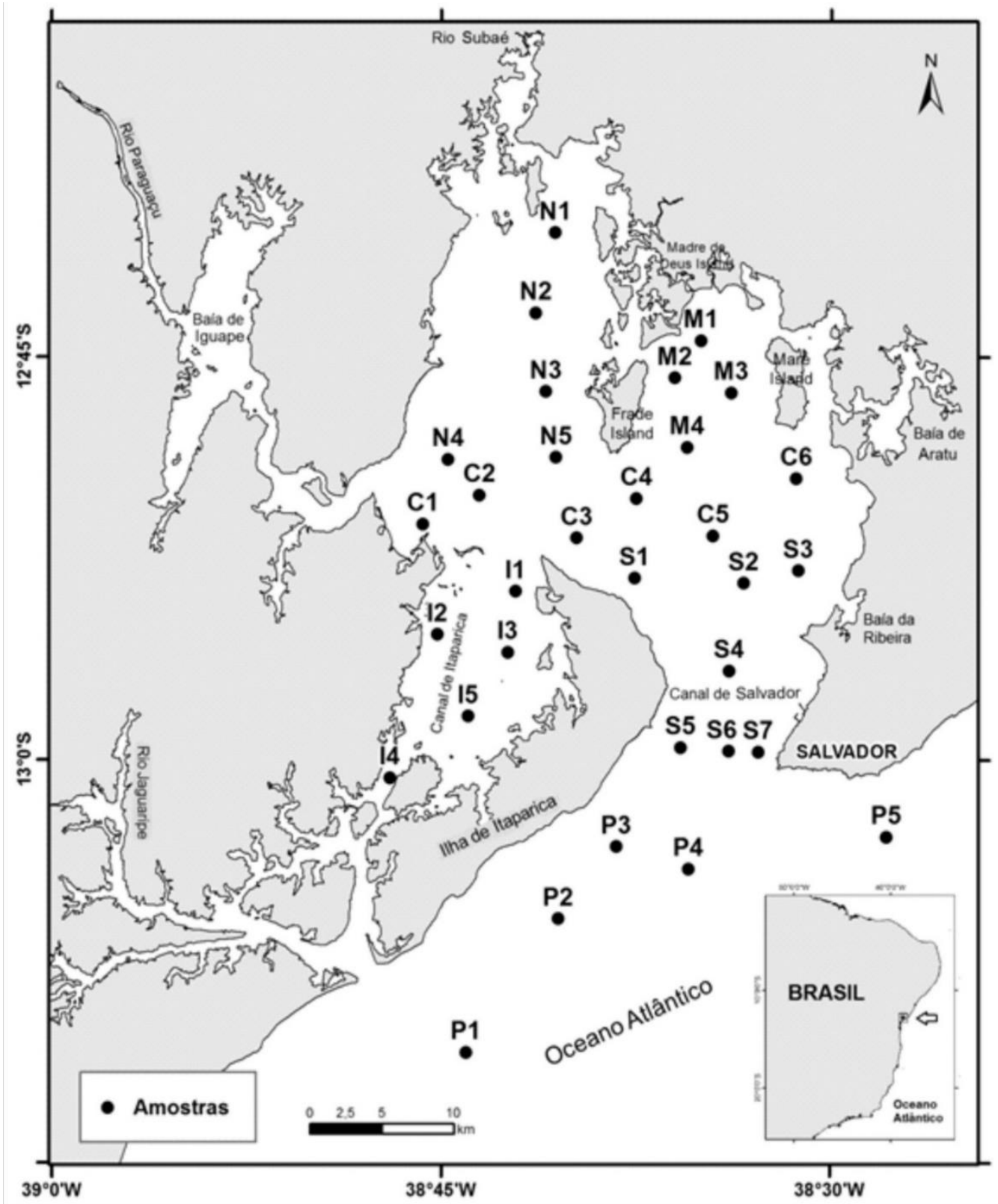

Figura 1 - Localização da área de estudo e das estações amostrais.

A composição dos sedimentos foi obtida analisando-se as primeiras 300 partículas de cada amostra, por fração granulométrica, até a fração areia fina $(>0,125 \mathrm{~mm})$ (Ginsburg, 1956; Purdy, 1963).

Dentre as partículas, aquelas de origem biológica, aqui referidas como biogênicas, foram identificadas a fim de determinar as biofácies da BTS. Para a identificação foram consideradas as características morfológicas definidas pelos espécimes de organismos que as originaram, observadas por meio de um estéreomicroscópio binocular (lupa), e as seguintes referências bibliográficas: Illing (1954), 
Milliman (1974), Skovsted (2006).

Os dados tafonômicos foram obtidos considerando as primeiras 150 partículas biogênicas (Kidwell et al., 2001), até a fração areia grossa $(>0,500 \mathrm{~mm})$. Foram considerados a fragmentação, o grau de arredondamento e a coloração dos grãos. A classificação da fragmentação e do grau de arredondamento seguiu a escala numérica proposta por Pilkey et al. (1967), na qual (0) representa grãos inteiros e sem arredondamento e (1) a (4) representam grãos fragmentados com diferentes níveis de arredondamento: (1) grãos muito pouco arredondados, (2) pouco arredondados, (3) arredondados e (4) muito arredondados.

Já a classificação da coloração dos grãos levouse em consideração que as cores branca (ou natural) e amarela representaram grãos sem alteração de cor, e as cores ocre, cinza e preta, grãos com alteração de cor, seguindo os critérios adaptados de Maiklem (1967) e Powell \& Davies (1990).

\section{Tratamento Estatístico dos Dados}

Para o tratamento dos dados, inicialmente, foi calculada a abundância relativa de cada um dos componentes do sedimento identificados em cada amostra. A interpretação dos resultados foi realizada com base nos valores obtidos, para cada componente, utilizando a seguinte classificação, de acordo com Dajoz (1983): (i) Principais, com abundância maior do que 5\%; (ii) Acessórios, com abundância entre 4,99 e 1\%, e (iii) Traço, com abundância menor do que $1 \%$. O valor do percentual final de cada componente foi resultante de ponderações feitas nas frações analisadas (Purdy, 1963; Gabrié \& Montaggioni, 1982).

A fim de determinar as biofácies da área de estudo foi realizada uma análise de classificação para agrupar objetos (modo Q), representados pelas estações amostrais, com base nos dados de abundância relativa apenas dos componentes biogênicos (Halfar et al., 2000).

Para tanto, foi empregado o método de Ward (variância mínima) conjugado com a distância euclidiana, utilizando o programa Statistica 9 for Windows. A significância dos agrupamentos foi obtida por meio do teste não-paramétrico MRPP (Multi-response permutation procedures), conforme Mccune \& Grace (2002), utilizando-se o programa $P C$-ORD 4.

O coeficiente de correlação $(r)$ foi estimado com o objetivo de medir a intensidade (\%) e o tipo (positiva ou negativa) da associação existente entre duas variáveis quantitativas (CallegariJacques, 2004). As variáveis dependentes consideradas foram os percentuais dos dados tafonômicos: grau de arredondamento (0-4) e coloração (branca, amarela, ocre, cinza, preta); e as variáveis independentes foram os parâmetros ambientais analisados: profundidade, teor de carbonato e lama nos sedimentos. Para dados paramétricos foi utilizado o coeficiente de correlação de Pearson e para dados nãoparamétricos o coeficiente de correlação de Spearman, utilizando o programa Graph Pad In Stat 3.

\section{RESULTADOS E DISCUSSÃO}

\section{Composição Biogênica dos Sedimentos}

A análise das partículas biogênicas na área de estudo permitiu identificar 16 taxa ou grandes grupos de organismos. Sete deles foram os mais abundantes e classificados como principais $(>5 \%)$ : molusco, alga Halimeda, equinodermo, briozoário, alga calcária não geniculada, alga calcária geniculada e foraminífero. Dentre estes, os dois primeiros, juntos, formaram $50,6 \%$ dos sedimentos biogênicos da baía. Os demais, crustáceo, cirrípede e pelota fecal, foram classificados como acessórios (4,99-1\%); e tubo de verme, ostracode, coral, porífero, octocoral e Millepora, foram classificados como traço $(<1 \%)$ (Figura 2$)$.

Dentre todas as partículas biogênicas identificadas, as espículas dos poríferos foram as únicas que apresentaram a sílica, além do carbonato de cálcio, na constituição de suas estruturas biomineralizadas.

As espículas silicosas foram as mais frequentes, ocorrendo em 58\% das amostras, principalmente na região norte da BTS, onde predomina o fundo lamoso.

Enquanto as espículas carbonáticas ocorreram em $42 \%$, predominando na saída da baía, onde podem ser encontrados fundos arenosos e duros, tais como bancos recifais. A presença de espículas silicosas em sedimentos tem sido considerada uma boa indicação da influência de água doce em ambientes costeiros (Volkmer-Ribeiro et al., 2004). A ocorrência destas na região norte da BTS e na desembocadura do rio Paraguaçu é um indicador dessa condição. 
Os moluscos, além de terem sido os componentes biogênicos mais abundantes $(28,5 \%)$ (Figura 2) nos sedimentos da Baía de Todos os Santos (BTS), ocorreram em todas as amostras analisadas. No estudo das comunidades bentônicas realizado por Alves et al. (2004), eles foram considerados como os principais orga- nismos presentes nas comunidades vivas da referida baía. Essa informação corrobora com os resultados do presente estudo, quando verificou o predomínio de conchas de moluscos compondo os sedimentos da BTS e explica o fato destes invertebrados contribuírem ativamente com a produção de sedimentos nesta região.

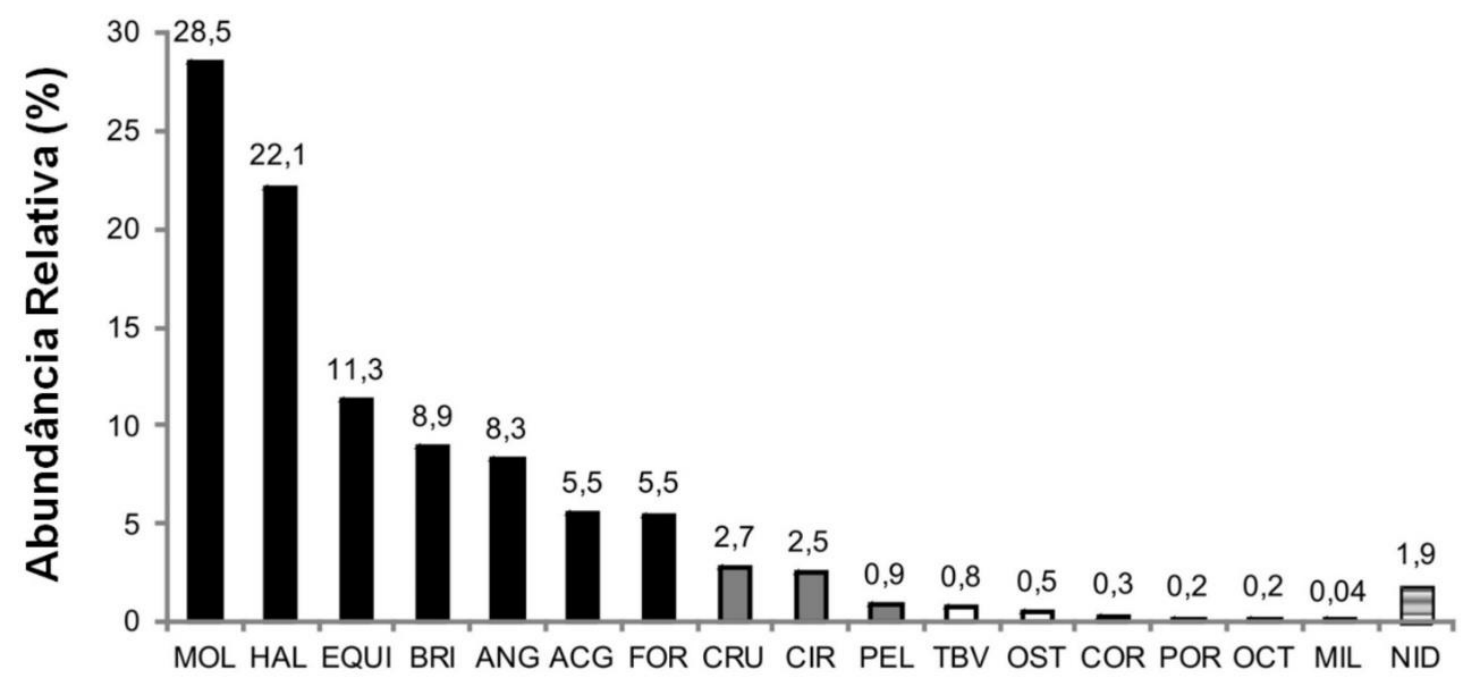

Figura 2 - Abundância relativa (\%) dos componentes biogênicos dos sedimentos da Baía de Todos os Santos. Onde: $\mathrm{MOL}=$ molusco, HAL=alga Halimeda, EQUI=equinodermo, BRI=briozoário, $\mathrm{ACNG=alga} \mathrm{calcária} \mathrm{não} \mathrm{geniculada,}$ $\mathrm{ACG}=$ alga calcária geniculada, $\mathrm{FOR}=$ foraminífero, $\mathrm{CRU}=$ crustáceo, $\mathrm{CIR}=$ cirrípede, $\mathrm{PEL}=$ pelota fecal, $\mathrm{TBV}=$ tubo de verme, OST=ostracode, $\mathrm{COR}=$ coral, $\mathrm{POR}=$ porifera, $\mathrm{OCT}=$ octocoral, $\mathrm{MIL}=$ hidrocoral Millepora, $\mathrm{NID}=$ não-identificado.

É reconhecida a importância dos moluscos na produção de sedimentos em ambiente de baías. Em um estudo realizado por Ginsburg (1956) foi constatado que os moluscos foram os constituintes principais dos sedimentos na Baía da Flórida, sul da Flórida; o mesmo ocorrendo no estudo realizado por Flessa et al. (1993), na Baía la Choya, no México; e no estudo realizado por Brooks \& Doyle (1998), na Baía de Tampa, costa oeste da Flórida.

Ao morrerem, os moluscos e outros organismos deixam suas partes biomineralizadas para compor os sedimentos, passando a se comportar como uma partícula sedimentar, mas com a peculiaridade de ter origem biológica. Assim, essas partículas biogênicas podem ser avaliadas como o reflexo das condições do ambiente em que são encontradas (Wright \& Burges, 2005) e consideradas como importantes objetos em estudos paleoecológicos.

Particularmente, as características morfológicas das conchas dos moluscos podem fornecer informações efetivas sobre diversas condições do ambiente (Stanley, 1975; Serb et al., 2011; Ayoub-Hannaa et al., 2012).

Conchas finas, por exemplo, são características de espécies que ocorrem soterradas em substrato lamoso e estável, e conchas espessas são comuns em espécies que habitam substratos arenosos móveis ou instáveis.

No presente estudo, os moluscos que ocorreram entre o Canal de Salvador e a plataforma apresentaram conchas espessas e resistentes e muitas vezes ornamentadas com espinhos e estrias, típicas de moluscos adaptados a um substrato arenoso ou rochoso, tal como encontrado nestas localidades.

Já ao norte da baía, onde há predomínio de lama, os moluscos apresentaram, em sua maioria, conchas mais delicadas, delgadas e lisas, típicas de moluscos adaptados a viverem em substratos lamosos. Essas observações sugerem pouco ou nenhum transporte dessas conchas, já que elas apresentam características morfológicas condizentes com ambiente em que foram encontradas.

Assim como os moluscos, as algas Halimeda também tiveram participação importante na constituição dos sedimentos da BTS. Elas foram bastante abundantes $(22,1 \%)$ e ocorreram em quase toda a área amostral, tanto em locais rasos como profundos, porém com menor abundância na região norte da baía.

De acordo com Flügel (1988), a alga 
Halimeda é frequentemente um dos constituintes mais abundantes em sedimentos de águas rasas. De fato, estas algas estavam entre os componentes dominantes em pontos rasos da BTS, principalmente naqueles localizados na região nordeste e no Canal de Itaparica, onde também foram verificados altos teores de carbonato nos sedimentos.

Nos locais profundos onde elas foram abundantes, como, por exemplo, no trecho mais estrito do Canal de Salvador, verificou-se que a maioria de seus artículos representavam grãos mal preservados e arredondados, sugerindo transporte.

Apesar da predominância dos moluscos e das algas Halimeda compondo os sedimentos biogênicos da BTS foi possível verificar a ocorrência de muitos outros constituintes. Essa diversidade biogênica é resultante da variabilidade das condições ambientais da baía, principalmente daquelas relacionadas aos tipos de fundo, caracterizados aqui pelas fácies sedimentares propostas por Dominguez \& Bittencourt (2009).

O estudo realizado por Alves et al. (2004), corrobora esta ideia, pois ficou constatada uma relação positiva entre a riqueza da fauna bentônica e a heterogeneidade dos sedimentos da referida baía.

Essa característica também pode ser considerada um dos principais fatores controladores da distribuição dos organismos produtores de sedimentos, pois foi possível observar uma estreita relação entre alguns deles e as características dos sedimentos de fundo.

Os crustáceos, ostracodes e poríferos, por exemplo, apesar de aparecerem de forma constante na área, foram os grupos mais abundantes na região norte da baía, onde existe bastante lama e matéria orgânica nos sedimentos.

Os dois primeiros são típicos comedores de detritos, e as espículas dos poríferos encontradas neste local são silicosas, características de espécies de esponjas que podem suportar variações de salinidade e que estão adaptadas a viverem ancoradas na lama (Ruppert et al., 2005).

Já os cnidários, corais e o hidrocoral Millepora, apresentaram ocorrência baixa nos sedimentos analisados da baía como um todo, estando completamente ausentes nas regiões central e norte, onde há altos teores de lama nos sedimentos.

Quando vivos, eles são bastante exigentes em termos de características ambientais, e estão adaptados às águas marinhas tropicais bem iluminadas e oxigenadas, além de exigirem a presença de um substrato rochoso para a fixação de suas larvas e o desenvolvimento de suas colônias (Ruppert et al., 2005).

Provavelmente, a pouca disponibilidade de um substrato adequado para o desenvolvimento destes cnidários não favorece a sua ocorrência e/ou processos tafonômicos agem de forma a não preservar seus restos biomineralizados na BTS.

\section{As Biofácies da BTS}

Os resultados obtidos por meio da análise de classificação apontaram a ocorrência de quatro biofácies significativamente diferentes entre si (MRPP, p<0,05). A figura 3 mostra o dendrograma resultante da análise de classificação, a composição e a distribuição das biofácies na BTS.

A tabela 1 apresenta um conjunto de características associadas a cada uma das biofácies, levando-se em consideração a localização, o tipo de fácies, os parâmetros ambientais e a tafonomia dos grãos (fragmentação, grau de arredondamento e coloração).

A biofácies alga-molusco - Grupo 1 - está constituída principalmente por algas calcárias não geniculadas associadas a Halimeda e a moluscos (Figura 3). Ela foi formada entre as amostras localizadas no Canal de Salvador (S) e na plataforma $(\mathrm{P})$, onde predominam sedimentos arenosos $(79,08 \%)$ constituindo a fácies areia quartzosa (Tabela 1).

Nessas amostras foram registradas, em média, as maiores profundidades e os maiores teores de areia e cascalho, bem como os menores teores de lama e matéria orgânica nos sedimentos.

O trecho referente ao Canal de Salvador é o mais estreito e é onde há registros de correntes significativamente fortes, capazes de impedir o acumulo de partículas finas, mas ao mesmo tempo, incapazes de transportar efetivamente as partículas maiores, que acabam ficando aprisionadas devido a grande profundidade da localidade.

Constatou-se também as maiores médias 
percentuais de grãos inteiros, arredondados e muito arredondados (Tabela 1).

Essas condições ocorreram possivelmente por causa da profundidade do canal. Os grãos inteiros que caem no canal permanecem assim por que não são transportados, mas ao mesmo tempo arredondam devido a circulação da água no local.
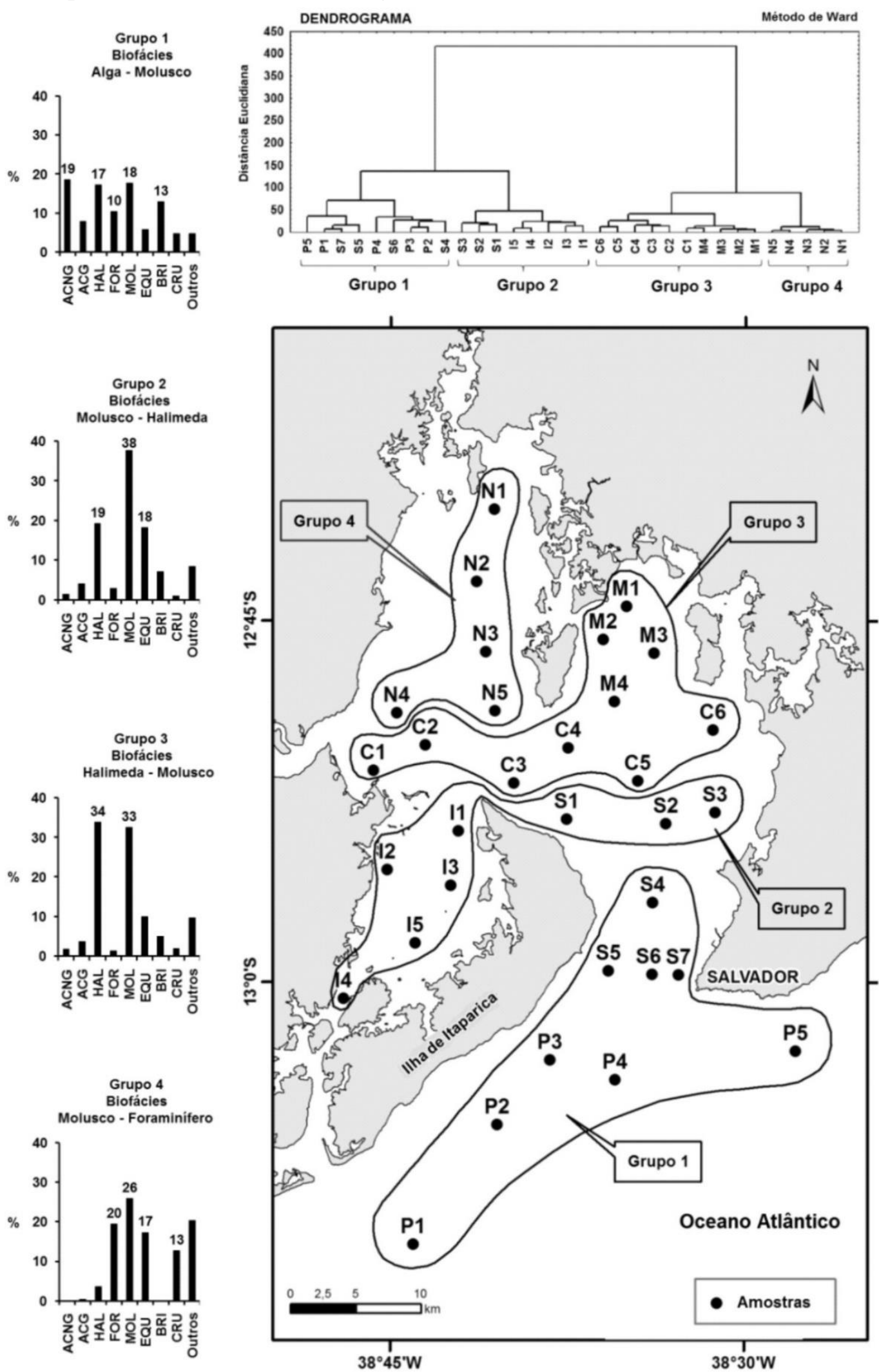

Figura 3 - Composição e distribuição das biofácies dos sedimentos da Baía de Todos os Santos. Onde: ACNG =alga calcária não geniculada, ACG =alga calcária geniculada, HAL=alga Halimeda, FOR=foraminífero, MOL=molusco, EQU =equinodermo, BRI=briozoário, $\mathrm{CRU}=$ crustáceo. O termo "Outros" refere-se ao somatório dos percentuais dos biogênicos menos representativos. 
Tabela 1 - Caracterização associadas às biofácies da Baía de Todos os Santos, considerando a localização, o tipo de fácies, os parâmetros ambientais e a tafonomia dos grãos. Onde: $0=$ grão inteiro, $1=$ muito pouco arredondado, $2=$ pouco arredondado, $3=$ arredondado e $4=$ muito arredondado. A classificação das fácies está de acordo com Dominguez \& Bittencourt (2009).

\begin{tabular}{|c|c|c|c|c|}
\hline \multirow[b]{2}{*}{ CARACTERÍSTICAS } & \multicolumn{4}{|c|}{ BIOFÁCIES } \\
\hline & $\begin{array}{c}\text { Alga- } \\
\text { Molusco } \\
\text { (Grupo 1) } \\
\end{array}$ & $\begin{array}{l}\text { Molusco- } \\
\text { Halimeda } \\
\text { (Grupo 2) } \\
\end{array}$ & $\begin{array}{l}\text { Halimeda- } \\
\text { Molusco } \\
\text { (Grupo 3) } \\
\end{array}$ & $\begin{array}{c}\text { Molusco- } \\
\text { Foraminífero } \\
\text { (Grupo 4) } \\
\end{array}$ \\
\hline $\begin{array}{l}\text { PRINCIPAIS } \\
\text { BIOGÊNICOS }\end{array}$ & $\begin{array}{l}\text { alga calcária não- } \\
\text { geniculada, } \\
\text { Halimeda, molusco }\end{array}$ & $\begin{array}{l}\text { molusco, } \\
\text { Halimeda, } \\
\text { equinodermo }\end{array}$ & $\begin{array}{l}\text { Halimeda, } \\
\text { molusco }\end{array}$ & $\begin{array}{l}\text { molusco, } \\
\text { foraminífero, } \\
\text { equinodermo }\end{array}$ \\
\hline LOCALIZAÇÃO & $\begin{array}{c}\text { Canal de Salvador e } \\
\text { Plataforma }\end{array}$ & $\begin{array}{c}\text { Canal de } \\
\text { Itaparica e Canal } \\
\text { de Salvador } \\
\end{array}$ & $\begin{array}{l}\text { Região central e } \\
\text { região nordeste }\end{array}$ & Região norte \\
\hline FÁCIES & Areia quartzosa & $\begin{array}{c}\text { Areias } \\
\text { biodetríticas e } \\
\text { areia quartzosa }\end{array}$ & $\begin{array}{c}\text { Mista, lama e } \\
\text { areias biodetríticas }\end{array}$ & Lama \\
\hline
\end{tabular}

\begin{tabular}{|c|c|c|c|c|c|c|}
\hline \multicolumn{7}{|c|}{ PARÂMETROS AMBIENTAIS } \\
\hline \multirow{6}{*}{ 茎 } & \multicolumn{2}{|c|}{ Profundidade (m) } & 25,36 & 18,39 & 14,37 & 8,40 \\
\hline & \multicolumn{2}{|c|}{ Carbonato $(\%)$} & 34,36 & 49,90 & 32,47 & 7,18 \\
\hline & \multicolumn{2}{|c|}{ Matéria Orgânica (\%) } & 1,32 & 3,26 & 5,80 & 10,40 \\
\hline & \multicolumn{2}{|c|}{ Cascalho (\%) } & 9,24 & 8,56 & 0,98 & 0,00 \\
\hline & \multicolumn{2}{|c|}{ Areia $(\%)$} & 79,08 & 52,55 & 32,90 & 5,22 \\
\hline & \multicolumn{2}{|c|}{ Lama $(\%)$} & 11,68 & 38,86 & 66,12 & 94,78 \\
\hline \multicolumn{7}{|c|}{ TAFONOMIA } \\
\hline \multirow{10}{*}{ 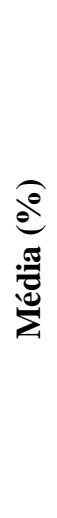 } & \multirow{5}{*}{ 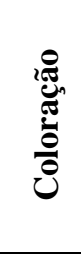 } & Branca & 1,90 & 3,09 & 8,67 & 0,63 \\
\hline & & Amarela & 31,59 & 57,14 & 76,19 & 90,79 \\
\hline & & Ocre & 32,42 & 3,06 & 0,52 & 1,33 \\
\hline & & Cinza & 32,15 & 36,42 & 14,62 & 7,25 \\
\hline & & Preta & 1,94 & 0,29 & 0,00 & 0,00 \\
\hline & \multirow{5}{*}{ 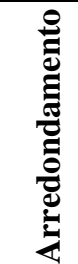 } & 0 & 11,54 & 10,47 & 9,63 & 0,00 \\
\hline & & 1 & 18,33 & 47,93 & 58,48 & 35,67 \\
\hline & & 2 & 44,91 & 37,11 & 28,47 & 48,78 \\
\hline & & 3 & 23,30 & 4,49 & 3,39 & 15,55 \\
\hline & & 4 & 1,92 & 0,00 & 0,03 & 0,00 \\
\hline
\end{tabular}

A biofácies molusco-Halimeda (Grupo 2), constituída principalmente por moluscos associados a Halimeda e equinodermos (Figura 3), foi formada entre as amostras do Canal de Itaparica (I) e aquelas do Canal de Salvador (S), adentrando a baía, onde os sedimentos são predominantemente arenosos (52,55\%) e constituem a fácies areias biodetríticas e areia quartzosa (Tabela 1).

Nessas amostras ocorreram, em média, os mais altos teores de carbonato $(49,90 \%)$ nos sedimentos em comparação com as demais estudadas. Os grãos se apresentaram predominantemente fragmentados $(89,53) \mathrm{e}$ foram classificados como muito pouco arredondados $(47,93 \%)$ e pouco arredondados $(37,11 \%)$, observando-se baixo percentual de grãos arredondados $(4,49)$ e nenhum grão muito arredondado (Tabela 1).

A biofácies Halimeda-molusco (Grupo 3), composta essencialmente por algas Halimeda e moluscos (Figura 3), foi formada entre as amostras das regiões central (C) e nordeste (M) da baía, onde ocorrem as fácies mista, lama e areias biodetríticas. Foram verificados, em média, teores altos de lama e matéria orgânica nos sedimentos assim como os maiores percentuais médios de grãos apresentando brilho, coloração branca e muito pouco arredondados (Tabela 1).

A biofácies molusco-foraminífero (Grupo 4), constituída principalmente por moluscos, associados a foraminíferos e equinodermos (Figura 3), foi formada entre as amostras da 
região norte $(\mathrm{N})$ da baía, onde predomina a fácies lama. Foram observados, em média, os maiores teores de lama e matéria orgânica nos sedimentos, e por outro lado os menores teores de carbonato e as menores profundidades, bem como os maiores percentuais médios de grãos com dissolução, com a coloração amarela e pouco arredondados. Nenhum grão inteiro ou muito arredondado foi observado (Tabela 1).

As associações biogênicas são formadas sob a influência de diversos fatores que envolvem o hábitat dos organismos e a preservação dos grãos produzidos por eles (Wright \& Burges, 2005). Na BTS, a heterogeneidade dos sedimentos surge como um fator decisivo, influenciando a formação dessas associações.

Elas ficaram tão bem definidas que foi possível observar uma clara transição da composição biogênica do interior da BTS, onde na maioria das vezes os moluscos predominaram nos sedimentos, em direção à plataforma adjacente, onde as algas calcárias passaram a ser o componente principal. Uma transição semelhante foi verificada por Ginsburg (1956), nos sedimentos biogênicos existentes entre a Baía da Florida e a barreira recifal estudados por ele. $\mathrm{O}$ autor constatou que os constituintes típicos do ambiente recifal, algas e corais, desapareceram gradativamente nos sedimentos à medida que adentrava a baía, vindo a predominar moluscos e foraminíferos.

\section{PROCESSOS TAFONÔMICOS}

Os processos tafonômicos analisados nos componentes biogênicos da Baía de Todos os Santos, fragmentação, grau de arredondamento e coloração, e suas correlações com os parâmetros ambientais profundidade, teor de carbonato e teor de lama, estão expressos na tabela 2.

Tabela 2. Processos tafonômicos atuantes nos componentes biogênicos da Baía de Todos os Santos e suas correlações com os parâmetros ambientais profundidade, teor de carbonato e teor de lama. Onde: $r=$ coeficiente de correlação, $p=$ significância do teste, $0=$ grão inteiro, $1=$ muito pouco arredondado, $2=$ pouco arredondado, $3=$ arredondado e $4=$ muito arredondado.

\begin{tabular}{|c|c|c|c|c|c|c|c|c|c|c|}
\hline \multirow{2}{*}{\multicolumn{3}{|c|}{$\begin{array}{c}\text { PROCESSOS } \\
\text { TAFONÔMICOS }\end{array}$}} & \multirow{3}{*}{$\begin{array}{c}\begin{array}{c}\text { Grãos } \\
(\%)\end{array} \\
11\end{array}$} & \multirow{3}{*}{$\begin{array}{c}\begin{array}{c}\text { Amostras } \\
(\%)\end{array} \\
75\end{array}$} & \multicolumn{2}{|c|}{ Profundidade (m) } & \multicolumn{2}{|c|}{$\begin{array}{c}\text { Teor de carbonato } \\
(\%)\end{array}$} & \multicolumn{2}{|c|}{ Teor de lama $(\%)$} \\
\hline & & & & & $r$ & $p$ & $r$ & $p$ & $r$ & $p$ \\
\hline \multirow{5}{*}{ 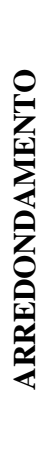 } & 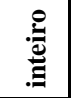 & $\mathbf{0}$ & & & 0,4335 & $0,0132 *$ & 0,3685 & $0,0380 *$ & $-0,5259$ & $0,0020 * *$ \\
\hline & 蓰 & 1 & 28 & 97 & 0,0495 & $0,7879 \mathrm{~ns}$ & $-0,2330$ & $0,1994 \mathrm{~ns}$ & 0,5798 & $0,0005 * * *$ \\
\hline & ¿ & 2 & 45 & 97 & $-0,1976$ & $0,2784 \mathrm{~ns}$ & 0,2365 & $0,1925 \mathrm{~ns}$ & $-0,3276$ & $0,0672 \mathrm{~ns}$ \\
\hline & $\stackrel{\overbrace{}}{\mathbb{Z}}$ & 3 & 14 & 75 & 0,1785 & $0,3284 \mathrm{~ns}$ & $-0,0680$ & $0,7116 \mathrm{~ns}$ & $-0,4137$ & $0,0186 *$ \\
\hline & 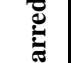 & 4 & 1 & 25 & 0,4002 & $0,0232 *$ & $-0,0198$ & $0,9140 \mathrm{~ns}$ & $-0,6256$ & $0,0001 * * *$ \\
\hline \multirow{5}{*}{ 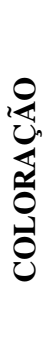 } & \multirow{2}{*}{ 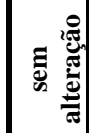 } & Branca & 5 & 63 & 0,1024 & $0,5771 \mathrm{~ns}$ & 0,3431 & $0,0545 \mathrm{~ns}$ & $-0,2664$ & $0,1405 \mathrm{~ns}$ \\
\hline & & Amarela & 48 & 100 & $-0,2917$ & $0,1053 \mathrm{~ns}$ & $-0,2232$ & $0,2195 \mathrm{~ns}$ & 0,6243 & $0,0001 * * *$ \\
\hline & \multirow{3}{*}{ 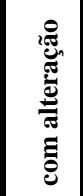 } & Ocre & 15 & 50 & 0,4520 & $0,0094 * *$ & 0,0294 & $0,8732 \mathrm{~ns}$ & $-0,5061$ & $0,0031 * *$ \\
\hline & & Cinza & 32 & 88 & 0,2113 & $0,2458 \mathrm{~ns}$ & 0,3036 & $0,0912 \mathrm{~ns}$ & $-0,4222$ & $0,0161 *$ \\
\hline & & Preta & 1 & 25 & 0,2639 & $0,1444 \mathrm{~ns}$ & 0,3208 & $0,0734 \mathrm{~ns}$ & $-0,5072$ & $0,0030 * *$ \\
\hline
\end{tabular}

Legenda: $\mathrm{ns}=$ não significativo $*$ significativo $* *=$ muito significativo $* * *=$ altamente significativo

\section{Fragmentação e Grau de Arredondamento} dos Grãos

O grau de arredondamento dos grãos biogênicos foi estimado de acordo com uma escala visual proposta por Pilkey et al. (1967). Segundo os autores, o arredondamento, juntamente com a fragmentação, é proporcional à energia do ambiente, assim a ocorrência de grãos inteiros e/ou numa escala menor de arredondamento indicaria baixa energia no ambiente.

$\mathrm{Na}$ BTS poucos grãos biogênicos foram encontrados inteiros (11\%), a maior parte estava fragmentada $(89 \%)$. Dentre os grãos fragmen- 
tados, predominaram aqueles classificados como pouco arredondados $(45 \%)$ ou muito pouco arredondados (28\%), com ampla ocorrência (97\% das amostras), sugerindo que, no geral, esta baía é um ambiente de baixa a moderada energia (Tabela 2). Esse resultado corrobora com a informação prestada por Lessa et al. (2001), que caracterizou a referida baía como um ambiente que apresenta correntes geralmente fracas, que ganham força apenas nos canais e constrições topográficas, principalmente na saída da mesma.

Os resultados também permitem concluir que a maioria das assembleias biogênicas da BTS podem ser classificadas como parautóctones, mais precisamente aquelas formadas pelos grupos 2, $3 \mathrm{e}$ 4 (Figura 3). Assembleias parautóctones são aquelas compostas por espécimes que sofreram retrabalhamento biológico (ação de bioturbadores) ou físico (ação de ondas e correntes), mas não foram transportadas para longe de seu hábitat original (Kidwell et al., 1986).

Os grãos biogênicos caracterizados como inteiros foram frequentes no ambiente sedimentar da BTS, ocorrendo em $75 \%$ da área de estudo, mas, como citado anteriormente, foram pouco abundantes, aparecendo em apenas $11 \%$ das amostras. Em $100 \%$ da área estudada foram encontrados grãos fragmentados, sendo essa condição predominante nas amostras (89\%).

Eles apresentaram correlação positiva com a profundidade e com o teor de carbonato, e negativa com o teor de lama no sedimento (Tabela 1). Alguns fatores parecem contribuir com este resultado. A ausência de bioturbadores e/ou a diminuição da ação das correntes nos locais mais profundos podem ter contribuído com a manutenção dos grãos inteiros.

Considerando-se que os ambientes carbonáticos são fonte de uma grande diversidade de grãos biogênicos (Milliman, 1974; Scoffin, 1992), eles também devem favorecer a reposição mais frequente desses grãos, o que possibilitaria verificar uma maior abundância de grãos inteiros neste tipo de ambiente. Já o motivo da baixa ocorrência de grãos inteiros onde há lama no sedimento, provavelmente, está relacionado à presença de atividade biológica (bioturbação e/ou predação) intensa nestes locais, já que a energia do ambiente não deve ser suficiente, nem para a fragmentação, nem para o arredondamento dos grãos.
Como também foi verificada uma correlação positiva dos grãos fragmentados e muito pouco arredondados (grau 1 de arredondamento) com a presença de lama nos sedimentos (Tabela 1), esta suposição pode ser verdadeira. A causa da fragmentação de grãos biogênicos pode ser mecânica ou biológica (Swinchatt, 1965).

A mecânica está relacionada com o nível de energia do ambiente e a biológica está relacionada com a ação de organismos bioturbadores e/ou a predação.

Os grãos com um nível maior de arredondamento (graus 3 e 4) foram pouco abundantes (14\% e $1 \%$, respectivamente) e apresentaram correlação negativa com a lama (Tabela 1). Eles foram mais abundantes nas regiões do Canal de Salvador e da plataforma onde os teores de lama nos sedimentos são baixos. Nestes lugares também foram encontrados grãos extremamente polidos (grau 4), sugerindo energia moderada a alta no ambiente.

Esses grãos, com arredondamento graus $3 \mathrm{e}$ 4, apresentaram correlação positiva com a profundidade (Tabela 1), sugerindo que eles são transportados até os locais mais profundos e ao ficarem aprisionados sofrem arredondamento naqueles locais, devido aos movimentos circulares da água. As assembleias biogênicas acumuladas no trecho mais estrito e profundo do Canal de Salvador, por exemplo, foram classificadas como alóctones no presente estudo, diferentes das demais, que foram classificadas como parautóctones.

As assembleias alóctones são aquelas compostas por espécimes transportadas para fora do seu hábitat de vida (Kidwell et al., 1986), e que, no caso daquelas presentes no Canal de Salvador, devem ser originárias dos ambientes recifais adjacentes e da plataforma continental. Ao verificar a composição dos grãos das amostras localizadas entre o Canal de Salvador e a plataforma, foi possível constatar, inclusive, que o transporte desses grãos ocorre preferencialmente em direção ao interior da baía, mas como o Canal de Salvador apresenta trechos muito profundos, ele acaba funcionando como uma barreira natural, impedindo que os grãos avancem para o interior da mesma.

Este fato deve ter contribuído bastante para a formação do Grupo 1 (biofácies alga-molusco), obtido na análise de classificação, o qual apresentou as algas calcárias, principalmente as 
não geniculadas e as Halimeda, como os principais componentes biogênicos das amostras localizadas entre o referido canal e a plataforma (Figura 3, Tabela 1).

\section{Coloração dos Grãos}

A coloração predominante entre os grãos biogênicos foi a amarela (48\%), e também a mais frequente na área de estudo, ocorrendo em $100 \%$ das amostras. A cor cinza foi a segunda mais observada entre os grãos $(32 \%)$ e também apresentou ampla distribuição na área (88\% das amostras). As demais cores, branca, ocre e preta, foram observadas em menos de $30 \%$ dos grãos analisados, no entanto a coloração branca apresentou frequência alta, ocorrendo em $63 \%$ das amostras, a cor ocre ocorreu em 50\% das amostras e a coloração preta ocorreu com baixa frequência na área, aparecendo em $25 \%$ das amostras (Tabela 2).

Considerando que as cores branca (ou natural) e amarela representaram grãos sem alteração de cor; e as cores ocre, cinza e preta, grãos com alteração de cor; ao somar os percentuais de cada classificação, observava-se que os biogênicos da BTS apresentaram pouco mais da metade dos grãos (53\%) sem alteração de cor. De acordo com Powell \& Davies (1990) e Mapes et al. (2010), os organismos produtores de sedimento tendem a manter alguma evidência da cor original e do brilho natural de suas carapaças por algum tempo, após a morte. Pode-se sugerir, então, que os biogênicos sem alteração na cor (branca ou amarela) e com brilho natural foram recentemente depositados e por isso devem contribuir ativamente para a produção de sedimentos na BTS. Estas condições ocorreram principalmente entre os biogênicos das regiões norte, nordeste e central da baía (Tabela 1).

Nessas regiões observa-se, de maneira geral, que as conchas de moluscos foram predominantes nos sedimentos (Figura 3) e por isso podem ser consideradas responsáveis pela condição preservada da coloração, reforçando o resultado anterior de que são o grupo de biogênicos que mais ativamente produz sedimentos recentes nesses trechos mais interiores da baía.

A cor amarela apresentou correlação positiva com o teor de lama no sedimento, sugerindo que a presença de lama pode estar favorecendo a ocorrência de grãos sem alteração de cor e, possivelmente, a preservação dos mesmos. A condição de preservação de grãos biogênicos em ambientes lamosos também foi verificada por Best \& Kidwell (2000).

Já as cores que representaram a condição alterada dos grãos (cinza, ocre ou preta) apresentaram correlação negativa com o teor de lama no sedimento, e foram mais abundantes no Canal de Itaparica, no Canal de Salvador e na plataforma (Tabela 1 e 2).

A coloração branca ou amarelada dos grãos pode estar associada a uma condição oxidante no ambiente e/ou a uma baixa taxa de retrabalhamento dos sedimentos, enquanto as cores ocre, cinza e preta podem indicar $\mathrm{o}$ inverso, ou seja, grãos que estavam soterrados estão sendo exumados periodicamente (Maiklem, 1967).

Sendo assim, o nível de retrabalhamento do sedimento foi menor nas regiões onde foi verificada a presença de grãos sem alteração de cor e significativos teores de lama nos sedimentos, como nas regiões norte, nordeste e central da baía. Já a presença de grãos com alteração de cor indica que o retrabalhamento do sedimento é mais intenso, e estaria ocorrendo no Canal de Itaparica, no Canal de Salvador e na plataforma (Tabela 2).

\section{CONSIDERAÇÕES FINAIS}

Os sedimentos biogênicos da Baía de Todos os Santos (BTS) apresentaram composição bastante diferenciada, no entanto os moluscos estão entre os constituintes predominantes em quase todos os setores da baía, não fugindo ao padrão composicional de ambientes semifechados semelhantes.

A grande diversidade de componentes biogênicos é resultante da variabilidade das condições ambientais da BTS, principalmente daquelas relacionadas aos tipos de fundo, caracterizados pelas fácies sedimentares propostas para esse ambiente. Essa diversidade possibilitou o reconhecimento de quatro biofácies, representadas por quatro diferentes associações de grãos biogênicos. Estas ocorreram em diferentes regiões da baía com características ambientais e tafonômicas distintas.

As condições de preservação dos grãos avaliadas variaram bastante em intensidade de 
acordo com as condições ambientais. De maneira geral, os sedimentos da BTS apresentaram-se fragmentados, uma condição que mostrou não estar associada a uma energia alta no ambiente, mas a outros fatores como, por exemplo, a atividade biológica (bioturbação e/ou predação) principalmente onde há predomínio de lama no sedimento.

Processos tafonômicos, tais como bioerosão e dissolução, também podem estar envolvidos na fragmentação dos grãos, mas estes não foram analisados no presente trabalho.

Os grãos também se mostraram, em sua maioria, sem alteração de cor, sugerindo produção ativa de sedimentos por parte dos principais organismos produtores, como os moluscos, por exemplo. Essa característica prioritária dos grãos pode indicar uma baixa taxa de retrabalhamento dos sedimentos na maior parte da área da baía.

Além disso, os grãos apresentaram-se geralmente pouco arredondados, confirmando a predominante condição de baixa a moderada energia no ambiente da baía, beneficiando a ocorrência de assembleias parautóctones compondo os sedimentos da mesma. Por fim, conclui-se que as biofácies refletiram uma complexa interação entre os múltiplos fatores envolvidos na sua formação e preservação.

\section{AGRADECIMENTOS}

C. A. Poggio agradece ao $\mathrm{CNPq}$ (Conselho Nacional de Desenvolvimento Científico e Tecnológico) pela concessão da bolsa de doutorado e aos demais autores sem os quais não seria possível o desenvolvimento e conclusão deste trabalho.

\section{REFERÊNCIAS}

ALVES, O.F.S.; MANSO, C.L.C.; ABSALÃO, R.S.; PAIVA, P.C. Geoecology of sublittoral benthic communities in Todosos Santos Bay (Bahia, Brazil): biotic and sedimentological diversity. Journal of Coastal Research, v. 39, Spec. Issue, p. 1152-1155, 2004.

AYOUB-HANNAA, W.; BENGTSON, P.; FÜRSICH, F.T.; ANDRADE, E.J. Megaporomya Reymenti Gen. et sp. nov. (Bivalvia, Pholadomyida) from the Upper Turonian (Upper Cretaceous) of the Sergipe Basin, North-Eastern Brazil. Revista Brasileira de Paleontologia, v. 16, p. 197 - 2012.

BEHRENSMEYER, A.K. \& KIDWELL, S.M. Taphonomy's contributions to paleobiology. Paleobiology, v. 11, p. 105$119,1985$.

BEHRENSMEYER, A.K.; KIDWELL, S.M.; GASTALDO, R.A. Taphonomy and Paleobiology. Paleobiology, v. 26, Spec. Issue, p. 103-147, 2000.

BEST, M.M.R. \& KIDWELL, S.M. Bivalve taphonomy in tropical mixed siliciclastic-carbonate settings: I. Environmental variation in shell condition. Paleobiology, v. 26, p. 80-102, 2000.

BITTENCOURT, A.C.S.P.; FERREIRA, Y.A.; DI NAPOLI, E. Alguns aspectos da sedimentação na Baía de Todos os Santos, Bahia. Revista Brasileira de Geociências, v. 6, p. 246-262, 1976.

BONETTI, C.; EICHLER, B.B.; DEBENAY, J.P. Evolução temporal da impactação do Sistema Estuarino de Santos-São Vicente (SP, Brasil) analisadas através das populações de foraminíferos sub-recentes. Revista Pesquisas em Geociências, v. 28, n. 2, p. 273-283, 2001.

BRETT, C.E. \& BAIRD, G.C. Comparative taphonomy: a key to paleoenvironmental interpretation basead on fossil preservation. Palaios, v.1, p. 207-227, 1986.

BROOKS, G.R. \& DOYLE, L.J. Recent sedimentary development of Tampa Bay, Florida: a microtidal estuary incised into Tertiary platform carbonates. Estuaries, v. 21, p. 391-406, 1998.

CALLENDER, W.R.; POWELL, E.N.; STAFF, G.M.; DAVIES, D.J. Distinguishing autochthony, parautochthony and allochthony using taphofacies analysis: can cold seep assemblages be discriminated from assemblages of the nearshore and continental shelf? Palaios, v. 7, p. 409-421, 1992.
CALLEGARI-JACQUES, S.M. Bioestatística: princípios e aplicações. Porto Alegre: Artmed, 255p., 2004.

DAJOZ, R. Ecologia Geral. 4. ed. Petrópolis: Vozes, 472p.,1983.

DOMINGUEZ, J.M.L. \& BITTENCOURT, A.C.S.P. Geologia. In: HATJE, V. \& ANDRADE, J.B. (Orgs), Baía de Todos os Santos. Aspectos Oceanográficos. Salvador: EDUFBA, p. 25-66, 2009.

DUTRA, L.X.C.; KIKUCHI, R.K.P.; LEÃO, Z.M.A.N. Todos os Santos Bay coral reefs, Eastern Brazil, revisited after 40 years. In: INTERNATIONAL CORAL REEF SYMPOSIUM, 10, 2004, Japan. Proceeding... Okinawa, Japan, 2006, v. 2, p. 1090-1095.

FLESSA, K.W.; CUTLER, A.H.; MELDAHL, K.H. Time e taphonomy: quantitative estimates of time-averaging and stratigraphic disorder in a shallow marine habitat. Paleobiology, v.19, p. 266-286, 1993.

FLÜGEL, E. Halimeda: paleontological record and palaeoenvironmental significance. Coral Reefs, v. 6, p. $123-$ 130,1988

GABRIÉ, C. \& MONTAGGIONI, L. Sediments from fringing reefs of Reunion Island, Indian Ocean. Sedimentary Geology, v 31, p. 281-301, 1982.

GINSBURG, R.N. Environmental relationship of grains size and constituent particles in some South Florida carbonates sediments. Bulletin - American Association of Petroleum Geologists, v. 40; p. 2381-2427, 1956.

GROSS, M.E. Carbon determination. In: CARVER, R. E. (Ed.). Procedures in sedimentary petrology. New York: Wiley Interscience, p. 573-596, 1971 .

HALFAR, J.; GODINEZ-ORTA， L.; INGLE JR, J.C. Microfacies analysis of Recent Carbonate Environments in the Southern Glf of California, Mexico - A model for warmtemperate to subtropical carbonate formation. Palaios, v. 15, p. 323-342, 2000 .

ILLING, L.V. Bahaman calcareous sands. Bulletin - American Association of Petroleum Geologists, v. 38, p. 1-95, 1954.

KIDWELL, S.M.; FÜRSICH, F.T.; AIGNER, T. Conceptual frameworkfortheanalysis and classification of fossilconcentrations. Palaios, v. 1, p. 228-238, 1986.

KIDWELL, S.M.; ROTHFUS, T.A.; BEST, M.M.R. Sensitivity of taphonomicsignatures to samplessize, sievesize, damagescoringsystem and target taxa. Palaios, v. 16, p. 25-52, 2001. 
LESS, A. \& BULLER, A.T. Modern temperate-water and warm-water shelf carbonate sediments contrasted. Marine Geology, v. 13, p. M67-M73, 1972.

LESSA, G.C.; BITTENCOURT, A.C.S.P.; BRICHTA, A.; DOMINGUEZ, J.M.L. A reevaluation of the late Quaternary sedimentation in Todosos Santos Bay (BA), Brazil. Anais da Academia Brasileira de Ciências, v. 72, n. 4, p. 573-590, 2000.

LESSA, G.C.; DOMINGUEZ, J.M.L.; BITTENCOURT, A.C.S.P.; BRICHTA, A. The tidal and tidal circulation of Todosos Santos Bay, Northeast Brazil: a general characterization. Anais da Academia Brasileira de Ciências, v. 73, n. 2, p. 245-261, 2001.

MAIKLEM, W.R. Black and brown speckled foraminiferal sand from the southern part of the Great Barrier Reef. Journal of Sedimentary Petrology, v. 37, p. 1023-1030, 1967.

MAPES, R.H.; LANDMAN, N.H.; COCHRAN, K.; GOIRAN, C.; FORGES, B.R.; RENFRO, A. Early taphonomy and significance of naturally submerged Nautilusshells from the New Caledonia region. Palaios, v. 25, p. 597-610, 2010.

McCUNE, B. \& GRACE, J.B. Analysis of Ecological Communities. Oregon: MJM Press, 300 p., 2002.

MILLIMAN, J.D. Marine carbonates. New York: Springer, 375 p., 1974.

PILKEY, O.H.; MORTON, R.W.; LUTERNAWER, J. The carbonate fraction of beach and dune sands. Sedimentology, v.8, p. 311-327, 1967.

POWELL, E.N. \& DAVIES, D.J. When is an "old" shell really old. The Journal of Geology, v. 98, p. 823-844, 1990.

PURDY, E.G. Recent calcium carbonate fácies of the Great Bahama Bank. 2. Sedimentaryfacies .The Journal of Geology., v. 71, p. 472-497, 1963.

RUPPERT, E.E.; FOX, R.S.; BARNES, R.D. Zoologia dos invertebrados: uma abordagem funcional-evolutiva.7. ed. São Paulo: Roca, 1145p., 2005.
SCOFFIN, T. P. Taphonomy of coral reefs: a review. Coral Reefs, v. 11, p. 57-77, 1992.

SERB, J.M.; ALEJANDRINO, A.; OTÁROLA-CASTILLO, E.; ADAMS, D.C. Morphological convergence of shell shape in distantly related scallop species (Mollusca: Pectinidae). Zoological Journal of the Linnean Society, n. 163, p. 571584, 2011.

SKOVSTED, C.B. Small shelly fauna from the upper lower Cambrian Bastion and Ella Island Formations, North-East Greenland. Journal of Paleontology, v. 80, p. 1087-1112, 2006.

SUGUIO, K. Introdução à Sedimentologia. São Paulo: Editora Blücher, 318 p., 1973.

STANLEY, S.M. Adaptive Themes in the Evolution of the Bivalvia (Mollusca). Annual Review of Earth and Planetary Sciences, v. 3, p. 361-385, 1975.

SWINCHATT, J.P. Significance of constituent composition, texture and skeletal breakdown in some recent carbonate sediments. Journal of Sedimentary Research, v. 35, p. 7190, 1965.

VOLKMER-RIBEIRO, C.; MOTTAMARQUES, D.; ROSABARBOSA, R.; MACHADO, V.S. Sponge Spicules in Sediments Indicate Evolution of Coastal Freshwater Bodies. Journal of Coastal Research, SI39, p. 469 - 472, 2004.

WRIGHT, V.P. \& BURGESS, P.M. The carbonate factory continuum, facies mosaics and microfácies: an appraisal of some of some of the key concepts underpinning carbonate sedimentology. Facies, v. 51, p. 17-23, 2005

Submetido em 22 de fevereiro de 2018 Aceito em 24 de outubro de 2018 